\title{
La capacitación campesina como instrumento de transformación del agro andino
}

\section{José Solís Mora}

Universidad Nacional San Antonio Abad del Cusco

RESUMEN

El ensayo trata de mostrar cómo los procesos de capacitación campesina diseñados en función del interés de los productores y acordes con su contexto sociocultural producen resultados positivos. Este caso demuestra los cambios alcanzados en los medios de vida de promotores campesinos denominados kamayoq en el transcurso de diez años en los Andes cusqueños, lo que, a su vez, demuestra que si se puede transformar la economía campesina a partir del mejoramiento de capacidades.

Palabras clave: capacitación campesina, tecnología, kamayoq, evaluación de impacto.

\section{Peasant's Training as an Instrument for the Transformation of Andean Agriculture}

ABSTRACT

The essay shows how methods of peasant training which are designed according to the interests of producers and according to their context have positive results. This case corroborates the changes in livelihoods of peasant promoters called kamayoq, that took place along ten years in the Cuzco Andes. It proves that it is possible to develop the rural economy improving peasant's skills.

Keywords: peasant capacitation, technology, kamayoq, impact evaluation. 


\section{INTRODUCCIÓN}

La experiencia de la «Escuela de kamayoq» forma parte de un proyecto de la ONG Soluciones Integrales - ITDG orientado a la formación de capacidades tecnológicas, impulsado entre 1997 y 2010. Los frutos de esta experiencia fueron campesinos minifundistas especializados (denominados kamayoq) que lograron desarrollar sus capacidades productivas y humanas para salir de la pobreza y generar cambios en sus medios de vida en un proceso de diez años. Para dicho análisis, realizamos en 2013 una evaluación de impacto cuyos resultados compartimos aquí. El objetivo del estudio fue explicar el modelo de capacitación de la «Escuela de kamayoq» y su influencia en el fortalecimiento de las habilidades tecnológicas agropecuarias de los promotores campesinos, así como evaluar los resultados e impactos generados por la capacitación técnica de los kamayoq en su vida personal y activos: capital natural, físico, financiero, humano y social.

La investigación evaluativa se realizó en el ámbito del proyecto, que comprendió 46 comunidades campesinas de los ocho distritos de la provincia de Canchis, perteneciente al departamento del Cusco, caracterizados por bajo nivel de desarrollo agrario y rural por causas harto conocidas: Bajo nivel de competitividad y rentabilidad agraria, alta fragmentación de la propiedad de la tierra, inadecuado uso y manejo de los recursos naturales, sobrepastoreo y capacidades limitadas de los productores agropecuarios. El proyecto se planteó como hipótesis que una manera de revertir esta situación era formar capacidades en los campesinos líderes - es decir, dotarlos de información y conocimientos tecnológicos agropecuarios - , para que estos a su vez las replicasen en sus comunidades. La propuesta institucional fue que dichos promotores se convirtiesen en extensionistas, es decir, en proveedores de asistencia técnica a las familias más pobres, las que no reciben apoyo estatal ni la presencia institucional privada. Para ello se diseñó la «Escuela de kamayoq». 
Los fundamentos de dicho programa de capacitación fueron la generación y difusión de tecnologías apropiadas, la preferencia por la producción en pequeña escala y por los productores de recursos escasos, el alto valor otorgado al conocimiento nativo y la cultura local, y la promoción del uso racional de los recursos naturales y la conservación del medio ambiente (De la Torre, 2004). Definidos los elementos centrales de su enfoque, se diseñó la implementación de la «Escuela de kamayoq», añadiéndole un componente intercultural altamente valioso que podemos resumir en cuatro aspectos.

El primero estaba relacionado con el «Comité Consejero», compuesto por los presidentes de las comunidades donde la ONG trabajaba y con quienes se deliberaban aspectos como la selección de participantes por comunidad. El segundo era que la capacitación práctica se realizaba en comunidades qollana, comunidades modelo donde la gran mayoría de familias había asumido propuestas tecnológicas agroecológicas y contaba con instalaciones mejoradas. El tercer aspecto intercultural de la propuesta fue el compromiso de que los campesinos capacitados y convertidos en kamayoq devuelvan y hagan su reciprocidad a su comunidad de origen en términos de enseñar y capacitar a las demás familias en las técnicas que les soliciten de manera gratuita o con recompensas simbólicas en productos o insumos. El cuarto tiene que ver con la consulta de la institución con las comunidades — en asambleas, talleres, ferias, concursos — para la gestión de la «Escuela de kamayoq», especialmente en los aspectos organizativos, en el desarrollo de temas y contenidos y en el seguimiento a los capacitados.

La ONG buscó formar promotores agropecuarios para que adquiriesen las siguientes capacidades: (i) ser un experto campesino en una o varias tecnologías agropecuarias (la categoría de experto significa que sus conocimientos sobre el tema son superiores al promedio en la zona), y (ii) ser proveedor de servicios de asistencia técnica en forma independiente.

La metodología para plasmar este diseño supuso que la capacitación se realizara mediante talleres de intercambio de saberes en las comunidades modelo, en las parcelas de los campesinos, en sus huertos y corrales, donde se realizaban intercambios de saberes entre los conocimientos campesinos y las tecnologías impartidas por los instructores y facilitadores. Otra modalidad fue el desarrollo de contenidos en talleres teórico-prácticos por especialistas en lugares distintos cada mes, es decir, en centros de experimentación, instituciones, comunidades, instalaciones privadas y otros, según la temática tratada. Este proceso ocupó de tres a cinco días al mes durante un año. 


\section{Resultados de la «Escuela de kamayoq»}

- 10 promociones, 389 egresados, 211 kamayoq activos.

- 46 comunidades campesinas involucradas, servicios de capacitación a 880 familias, 2000 personas beneficiadas indirectamente.

- 18 instituciones públicas y ONG de desarrollo han contratado servicios de 30 kamayoq como instructores en proyectos de Cusco, Apurímac y Ayacucho.

La metodología para la evaluación del impacto de la experiencia de formación de promotores campesinos que permitió desarrollar las capacidades de campesinos canchinos considera las siguientes perspectivas: (i) en el campo metodológico del impacto que ha tenido la capacitación, miramos desde la óptica de los mismos kamayoq, de los propios actores; para ello, recurriremos a testimonios e historias de vida, y también a encuestas, entrevistas, grupos focales, talleres participativos y observación participativa; (ii) en el campo teórico, utilizamos los instrumentos conceptuales de la teoría de los medios de vida y del desarrollo humano para analizar los cambios ocurridos en los promotores y en las comunidades campesinas.

\section{CAMBIOS EN LOS MEDIOS DE VIDA DE LOS KAMAYOQ}

\section{En el capital natural}

El capital natural de las familias campesinas constituye la base de su subsistencia y desarrollo económico, el cual está compuesto por los recursos naturales, tanto comunales-colectivos (tierras, agua, pastos naturales, bosques, biodiversidad) como privados (tierras, ganados, bosques). En esa medida, desarrollan la organización de su economía en su predio, el cual se sustenta en la fuerza del trabajo familiar. Es precisamente esta dinámica asociativa y comunal la que permite que se reproduzca la familia campesina. En el caso de los kamayoq, ellos lograron optimizar y potenciar sus escasos recursos naturales sobre la base de su empoderamiento cognitivo, de habilidades y prácticas tecnológicas que aplicaron y validaron en sus propias fincas.

El proceso por el cual los kamayoq han ido incrementando y potenciando los activos naturales en sus predios tardadó entre tres y cinco años, con inversiones graduales de capitales económicos ${ }^{1}$ y sustanciales de mano de obra familiar. Así, tenemos que:

Es decir, préstamos de sus familiares, venta de sus animales o apoyo económico de sus hijos mayores que les han permitido realizar las mejoras en sus terrenos, ganados, huertos, instalaciones e insumos. 
- Para el suelo: aplicaron abono natural, instalaron composteras y lombricultura en sus predios; también humus, biol, abono verde y prácticas de conservación de suelos como terrazas, surcos en contorno y agroforestería, además de realizar rotación y asociación de cultivos.

- Para los cultivos: incorporaron nuevos cultivos, como pastos, forrajes y hortalizas, así como nuevas variedades mejoradas en sus cultivos tradicionales, como papa, maíz, trigo, cebada, quinua, haba y otros.

- Para sus crianzas: instalaron canchas, cobertizos, comederos, corrales, también construyeron galpones para cuyes, gallinas, así como adquirieron equipos veterinarios, medicinas y vitaminas. También mejoraron dichos ganados genéticamente con padrillos de otros lugares.

- Para alimentación animal: sembraron forrajes y pastos cultivados, hicieron ensilados y henificación de forrajes, transplante de semillas naturales y aprovechamiento de humedales para la alimentación de alpacas, raciones autoproducidas en las propias fincas.

- Para el agua: adquisición de equipos de riego por aspersión, construcción de pequeños reservorios, captación de manantes y pequeños canales.

Los kamayoq encontraron en su proceso formativo una oportunidad para darse cuenta de las carencias y comenzaron a mirar de otra manera sus propias prácticas de (i) re-crear las técnicas propias, (ii) aplicar otras técnicas pertinentes a la solución de sus problemas y (iii) tomar la decisión para mejorar sus activos naturales en sus propias fincas familiares. Es decir, se dieron cuenta que habían mejorado la calidad de sus tierras de cultivo, ganado, pastos y manejo del agua. Según la información recogida en campo, la demostración más evidente se halla en las transformaciones e incrementos en cada uno de los componentes de su sistema de producción agrícola y pecuario que están enteramente vinculados con la manera como los kamayoq han logrado modificar y optimizar sus activos naturales, que articulados se van a evidenciar en mejoras sustanciales que van a producir efectos multiplicadores. En los siguientes cuadros presentamos las expresiones de dichos impactos en el capital natural de los kamayoq: 


\section{Cuadro 1. Índices de análisis}

Índice de análisis: «mejora de suelos»

Aplica solo abono natural

Usa guano de corral y composteras

Posee humus, composteras, realiza rotación de cultivos

Usa humus, composteras, biol, realiza rotación cultivos y algunas terrazas

Usa humus, composteras, biol, realiza rotación cultivos, posee terrazas y agroforestería

\begin{tabular}{lcc}
\hline Total & 140 & 100 \\
\hline Índice de análisis: «mejora de cultivos» & Cant. & \% \\
\hline Usa semillas comunes, mezcladas & 8 & 5,71 \\
Selecciona poco las semillas de su finca & 10 & 7,14 \\
Selecciona semillas de calidad e introduce nuevos cultivos como hortalizas & 37 & 26,42 \\
Selecciona semillas de calidad, produce hortalizas e introduce pastos & 42 & 30,0 \\
cultivados & & \\
Produce permanentemente pastos, hortalizas y usa semillas nuevas & 43 & 30,71 \\
mejoradas & & \\
\hline
\end{tabular}

Cant. \%

$5 \quad 3,57$

117,85

3927,86

$45 \quad 32,14$

$40 \quad 28,57$

\begin{tabular}{lcc}
\hline Total & 140 & 100 \\
\hline Índice de análisis: «manejo ganadero» & Cant. & \% \\
\hline Cría sus animales de manera tradicional /común & 4 & 2,85 \\
Cuenta con corrales y cobertizos rústicos & 17 & 12,14 \\
Tiene cobertizos, establos, canchas y cuyerías bien manejadas & 29 & 20,71 \\
Cuenta con infraestructura completa para animales mayores y menores. & 39 & 27,85 \\
Realiza pastoreo semiestabulado & & \\
Cuenta con infraestructura completa para animales mayores y menores. & 51 & 36,42 \\
Realiza pastoreo estabulado. Posee equipos de sanidad & & \\
\hline Total & 140 & 100 \\
\hline & & \\
\hline Índice de análisis: «alimentación animal» & 12 & 8,57 \\
\hline Alimenta a sus animales con pastos naturales y chala de maíz & 15 & 10,71 \\
Sus animales se alimentan con pastos naturales y cultivados & 45 & 32,14 \\
Cambia sus animales criollos por animales mejorados & 35 & 25,00 \\
Compra y hace engordar vacunos y ovinos con alimento concentrado y & & \\
pastos mejorados & 33 & 23,57 \\
Tiene solo animales mejorados, pasto cultivado y cuenta con mayor & & \\
producción de leche, carne y fibra & 140 & 100 \\
\hline Total & & \\
\hline
\end{tabular}

Fuente: Evaluación de impacto, 2013. 
Lo interesante de este incremento en el capital natural fue que los kamayoq realizaron dichas inversiones sobre sus recursos en el transcurso de varios años de manera progresiva a partir del método prueba-error-prueba y lograron cambiar la configuración de sus viviendas bajo el diseño predial agroecológico, donde se distribuye las instalaciones de cultivos y crianzas en una dinámica de flujos muy intensa. Este incremento también se dio en sus parcelas grandes de riego y secano, donde aplicaron técnicas acordes a cada realidad específica en función de su altura, zona de producción y microclimas. Así por ejemplo, en las punas, donde muchos kamayoq tienen alpacas, su mayor preocupación fue garantizar la alimentación y sanidad de los animales; en cambio en el piso de valle el manejo ha sido mixto y es donde mayor inversión económica, social y de mano de obra han realizado.

A continuación presentamos algunos testimonios:

Yo he trabajado en mis propios ganados, he realizado mejoramiento genético de alpacas, instalación de pastos mejorados y crianza mejorada de cuyes. También he hecho la construcción de galpón para cuyes. En la agricultura he trabajado en agroforestería; en altura, al contorno del cultivo de papas nativas he colocado ichus (Sergio Mamani, comunidad de Mamuera, distrito de Maranganí).

He realizado el mejoramiento de semillas de habas, yo cultivé la variedad munay angélica y mis vecinos me compraron todo, ni para mi consumo me ha quedado. Les he enseñado a cultivar en surcos más anchos con la técnica de sembrío a golpe, ya no por voleo o por chorros, lo cual primero experimento en mi parcela y luego recomiendo a mis clientes con certeza (Nicolás Fuentes, comunidad Puchuri).

Los impactos sustanciales del incremento en los activos naturales de los kamayoq se han dado en el incremento de los rendimientos agrícolas, doble cosecha de hortalizas, el vender en el mercado subproductos pecuarios como carne, leche, fibra y lana, así como animales mejorados o engordados en vacunos y ovinos. En el caso de animales menores, el impacto ha sido mayor por la rapidez en la obtención de las ganancias y la conversión veloz de forraje en carne. Este cambio se debió a la correcta aplicación tecnológica, a la eficiente administración de las fincas familiares en el marco de manejar los flujos de energía de los cultivos y de las crianzas, y a la gestión para organizar el sistema de policultivos, manejo de suelos y labores agrícolas. 
En cuanto a las actividades pecuarias, los principales cambios en sus predios familiares fueron ejecutar prácticas de sanidad aplicadas rigurosamente en los animales de su rebaño a lo largo de la campaña pecuaria. Asimismo, aplicaron en sus rebaños técnicas de crianza, empadre, descole, destete, cruzamiento y otros realizados por los kamayoq, así como técnicas de alimentación: pastoreo, henificación, ensilado, estabulación, semiestabulado, y técnicas de manejo de pastos cultivados: siembra, densidad, cortes, abonamiento, etc.

\section{En el capital físico}

Como consecuencia de los mayores ingresos alcanzados en el desarrollo del capital natural en sus productos agrícolas, y principalmente pecuarios, los kamayoq consideraron que dichos ingresos debían servir para mejorar la economía familiar en dos dimensiones: productiva y reproductiva.

Las inversiones productivas son aquellas dirigidas a incrementar sus activos orientados a mejorar su producción agrícola, ganadera, generación de autoempleo y facilitar los costos de transacción para la comercialización de ganado vacuno: vacunos, ovinos y alpacas. No fue casual que las familias de los kamayoq priorizaran un conjunto de compras de insumos agrícolas y ganaderos, instalaciones como galpones, centros de engorde, maquinaria, equipos, herramientas, módulos de riego por aspersión, botiquín veterinario y otros, con el fin de seguir dinamizando sus capitales naturales. Ellos intuitivamente consideraron que comprar dichos bienes de capital los conduciría a mayores retos y a la ampliación de su producción y productividad.

Las inversiones reproductivas o domésticas son los aspectos orientados a la mejora de la calidad de vida de la familia del kamayoq referidas a «gastos» en la mejora de la vivienda, acceso a servicios, compra de bienes duraderos, ropa, vehículos y hasta inmuebles. Tomando como base el año 2003, en comparación con 2009, es interesante descubrir de qué manera los kamayoq han invertido sus ingresos: especialmente en bienes de capital, instalaciones productivas, servicios básicos y bienes de capital, en ese orden. Con todo ello han incrementado sustancialmente su capital físico y realizado inversiones que les han resultado positivas en términos de mayor producción y productividad, de tener más menos riesgos y de ser menos vulnerables a los riesgos climáticos y económicos. 
Cuadro 2. Incremento de activos físicos de los kamayoq

\begin{tabular}{lcclcc}
\hline & \multicolumn{2}{c}{ Antes } & Ahora & Antes & Ahora \\
Activos fisicos & N. kamay. & N. kamay. & N. kam. & N. kam. \\
\hline Agua potable & 40 & 93 & Cerdos & 13 & $\mathbf{1 7}$ \\
Arado & 26 & 30 & Cuyes & 91 & $\mathbf{9 3}$ \\
Mochila fumigadora & 18 & 67 & Gallinas & 56 & $\mathbf{5 4}$ \\
Equipo veterinario & 15 & 89 & Patos & 12 & $\mathbf{9}$ \\
Mallas & 18 & 37 & Bienes de consumo & & \\
Esquiladora & 13 & 18 & Televisión & 73 & $\mathbf{1 1 4}$ \\
Trilladora manual & -- & 1 & Radio & 126 & $\mathbf{1 3 6}$ \\
Equipo riego por & & & & & \\
aspersión & 4 & 54 & Bicicleta & 93 & $\mathbf{1 1 2}$ \\
Manguera & 17 & 72 & Triciclo & 34 & $\mathbf{5 2}$ \\
Pala, pico & 127 & 134 & Equipo de sonido & 18 & $\mathbf{5 7}$ \\
Chakitaclla & 118 & 127 & Teléfono & 2 & $\mathbf{3 5}$ \\
Activos naturales & & & Celular & 3 & $\mathbf{5 7}$ \\
Ganado vacuno & & & & & \\
criollo & 94 & 83 & & & \\
Ganado mejorado & 15 & 80 & Otros & & \\
Ganado ovino criollo & 82 & 79 & Agua potable & 10 & $\mathbf{6 5}$ \\
Ovino mejorado & 9 & 52 & Desagüe & 6 & $\mathbf{1 7}$ \\
Alpacas mejoradas & 45 & 52 & Electricidad & 12 & $\mathbf{5 8}$ \\
Llamas & 30 & 29 & & & \\
Caballos & 39 & 43 & & & \\
Burros & 19 & 22 & & & \\
\hline
\end{tabular}

Evaluación de impacto, 2013.

Interesante es que, en comparación con las demás familias de la comunidad, el peso de las inversiones productivas que realiza el kamayoq es mayor. Así, tenemos que una familia campesina invierte aproximadamente el $40 \%$ de sus ingresos en la compra de bienes de consumo (radio, reloj, televisión, bicicleta, celular y otros) y $10 \%$ para la compra de bienes de capital agropecuario. Los kamayoq — gracias a su formación — tienen una actitud distinta: optan por la adquisición de insumos, equipos, instalaciones, herramientas o pequeñasmáquinas 
para impulsar sus nuevas actividades, destinando a ellos aproximadamente el $60 \%$ de sus ingresos; el resto para la educación de sus hijos, bienes de consumo y alimentación. Este monto también va teniendo algunos matices. Por ejemplo, cuando la familia del kamayoq es joven y tienen hijos en edad escolar, el monto destinado a la inversión productiva es mayor; a medida que los hijos crecen, el monto disminuye, pero una vez que estos son jóvenes, el monto aumenta, dado que aportan en la mano de obra familiar.

\section{En el capital financiero}

Las fuentes de ingreso de los kamayoq son de tres tipos:

\section{Cuadro 3. Fuentes de ingreso de los kamayoq}

\begin{tabular}{lll}
\hline \multicolumn{1}{c}{$\begin{array}{c}\text { Actividades tradicionales } \\
\text { diversas }\end{array}$} & \multicolumn{1}{c}{$\begin{array}{c}\text { Ingresos por ser } \\
\text { promotores }\end{array}$} & \multicolumn{1}{c}{\begin{tabular}{c}
\multicolumn{1}{c}{ Ingresos por } \\
emprendimientos
\end{tabular}} \\
\hline $\begin{array}{l}\text { Venta de productos agrícolas } \\
\text { en los mercados locales }\end{array}$ & $\begin{array}{l}\text { Asistencia técnica } \\
\text { Contratados por }\end{array}$ & $\begin{array}{l}\text { Comercialización de semillas } \\
\text { mejoradas, hortalizas }\end{array}$ \\
Venta de crianzas & instituciones & $\begin{array}{l}\text { Comercialización de animales } \\
\text { mejorados }\end{array}$ \\
Otros: tricicleros, albañil, & & Transformación de lácteos y otros \\
carpintería, vendedor ambulante & &
\end{tabular}

Estudio de impacto, 2013.

Ingresos por actividades tradicionales

Nos referimos a ingresos provenientes de la comercialización de ganados y de actividades complementarias diversas (albañil, obrero, ambulante, triciclero, carpintero y otros), donde se incluía la venta de productos agrícolas al menudeo, como de algunos animales en las tabladas. El cambio sustancial en la composición del ingreso familiar se da a partir de que los kamayoq se insertan en dos nuevas actividades: (i) como proveedores de asistencia técnica, y (ii) como impulsores de emprendimientos nuevos, que abren las posibilidades a nuevas fuentes de ingreso por producción de cuyes, artesanía y por microempresas familiares (engorde, producción de ovinos mejorados, crianza de alpacas, comercialización de fibra, carne de alpaca).

Hemos calculado los ingresos referidos a actividades tradicionales a partir de las encuestas realizadas en el estudio de impacto. Si tomamos como año base 2003, los kamayoq recibían un ingreso de 110 soles por otras actividades. Para el 
año 2009, el ingreso promedio mensual por estas actividades es de 150 soles, lo que significa que han incrementado sus ingresos 40 soles en seis años $(16,7 \%)$. Si consideramos que la inflación en promedio ha sido 3,5\% anual, en seis años ha sido del 21,0\% acumulado; entonces, el déficit es notorio.

Ingresos de los kamayoq en su rol de asistencia técnica

En el rol de oferentes de asistencia técnica, los kamayoq al inicio tuvieron ingresos regulares que los entusiasmaron grandemente (promedio 200 soles), pero conforme aparecían más kamayoq, la competencia se hizo más dura, los ingresos bajaron y terminaron oscilando entre 80 y 100 soles mensuales. Analizando la información de la estructura de ingresos de los kamayoq, se puede entrever una situación que contrarresta la visión de la ONG, según la cual los kamayoq, en su rol de oferentes de asistencia técnica, iban a «mejorar sus ingresos y vivir de ellos». La realidad es que ello nunca ocurrió, ni tampoco pudo darse. La razón es estructural y tiene que ver con la lógica económica de las familias campesinas, para quienes la asistencia técnica no tiene valor económico: en las familias el enseñar, capacitar, no tiene valor monetario, no forma parte de su cultura económica ${ }^{2}$. Es por tal razón que los kamayoq, que al inicio se deslumbraron con sus ingresos, con el tiempo se dieron cuenta de que no eran sostenibles. La mayoría manifiesta que los ingresos como proveedor de asistencia técnica son «una ayuda», que « salva de apuros», pero que no es posible vivir de ser kamayoq

Según los datos recogidos en campo, y comprobando el poco valor que se da al conocimiento desde la perspectiva campesino-indígena, por el costo de los conocimientos agrícolas que da el kamayoq solo paga el $2 \%$ de los comuneros que reciben el servicio; cuando la asistencia técnica es ganadera, solo paga el $18 \%$. En caso de que el kamayoq acompañe a la asistencia técnica insumos veterinarios (vitaminas, medicinas), entonces el nivel de reconocimiento monetario varía: llega a pagar el $42 \%$ de las familias campesinas receptoras. En el caso de la agricultura, cuando la asistencia técnica va asociada a la provisión de insumos (pesticidas, biol) por el kamayoq, paga el $21 \%$ de las familias que reciben dicho servicio.

2 Dentro de un enfoque del mercado informal (no mercado) sustentado en relaciones interpersonales, orientado a la subsistencia bajo parámetros de reciprocidad, la información técnica para el mundo campesino «no tiene valor económico», dado que el conocimiento se trasmite de generación en generación y este tiene carácter social, no cuesta. En la medida en que el conocimiento se va haciendo cada vez más especializado y hay una demanda creciente de este, cobra un «valor de cambio» que entra a la esfera de la oferta y demanda del mercado y se vuelve comercializable. 
En resumen, entonces, tenemos la carencia de una «cultura del pago de servicios entre comuneros $»^{3}$, pero también hay un factor estructural, dado que las familias campesinas no disponen de suficientes recursos económicos para pagar dicho trabajo debido a los altos niveles de pobreza. Por dichas razones, la sostenibilidad de un mercado de asistencia técnica moderno en el sentido clásico no es viable. Más aun si son familias comunitarias bajo condiciones de una predominante economía campesina y cuyo vínculo con el mercado es gradual, parcial y temporal. Para que se abran las posibilidades de un mercado de asistencia técnica tendrán que ocurrir cambios estructurales en el agro, lo que se relaciona con otros factores ${ }^{4}$.

Ingresos de los kamayoq por emprendimientos

La apertura de nuevas posibilidades de generación de ingresos ha significado enormes cambios en la lógica campesina de acceso al mercado dinámico a partir de la producción y comercialización de cuyes, animales mejorados, producción de alfalfa, hortalizas y otros. Esto ha ido rompiendo su «racionalismo tradicional productivo» y los ha catapultado hacia el cambio tecnológico y, por lo tanto, a la ampliación de las posibilidades de insertarse en el mercado de bienes y servicios de manera positiva. Con los nuevos negocios iniciados, los kamayoq hacen un giro extraordinario en la composición de la estructura de ingresos familiar, dado que involucran a los demás miembros de la familia y los impulsan a quedarse en la finca o en la comunidad, lo que garantiza que la mano de obra familiar se optimice para invertirla en los trabajos de la finca familiar.

Los emprendimientos indicados están en función de características propias de cada familia de los kamayoq; es decir, según su experticia, el conocimiento, su vocación, el tiempo disponible, los roles de varones y mujeres, el apoyo de la esposa e hijos, la facilidad del manejo y la disponibilidad del recurso. Las actividades más rentables para el piso de valle son la crianza de cuyes y el engorde de vacunos; para el piso de altura, la crianza de alpacas y la venta de ovinos mejorados. Dichos emprendimientos son priorizados — según expresan los kamayoq - porque son de fácil venta, se reproducen rápidamente, el tiempo de inversión es corto y existe ya un mercado conocido.

3 Debido a la predominancia de relaciones propias de la economía campesina y a su débil inserción en el mercado de trabajo.

4 Transformaciones de las relaciones de propiedad de la tierra (mercado de tierras), ampliación del mercado de bienes y servicios, operadores crediticios, producción orientada al mercado, libre competencia, así como la proletarización del campesino e inversiones agrarias externas. 
Cuadro 4. Tipos de emprendimientos ejecutados por los kamayoq

\begin{tabular}{llll}
\hline Rubro agrícola & Rubro ganadero & Transformación & Otros \\
\hline $\begin{array}{l}\text { Producción y } \\
\text { venta de semillas } \\
\text { mejoradas }\end{array}$ & $\begin{array}{l}\text { Engorde de ganado vacuno } \\
\text { y ovino }\end{array}$ & $\begin{array}{l}\text { Producción de } \\
\text { yogur y queso }\end{array}$ & $\begin{array}{l}\text { Venta de leche } \\
\text { y alfalfa }\end{array}$ \\
\hline $\begin{array}{l}\text { Producción y venta } \\
\text { de hortalizas }\end{array}$ & $\begin{array}{l}\text { Crianza y venta de animales } \\
\text { mejorados (alpacas, ovinos, } \\
\text { vacunos, porcinos y cuyes) }\end{array}$ & $\begin{array}{l}\text { mermeladas y } \\
\text { miel }\end{array}$ & $\begin{array}{l}\text { Venta de fibra, } \\
\text { lana y carne }\end{array}$ \\
\hline $\begin{array}{l}\text { Producción y venta } \\
\text { de humus }\end{array}$ & $\begin{array}{l}\text { Manejo y venta de } \\
\text { reproductores de cuy, } \\
\text { alpacas, ovinos }\end{array}$ & $\begin{array}{l}\text { Confección de } \\
\text { prendas de alpaca }\end{array}$ & $\begin{array}{l}\text { Guías locales } \\
\text { para turismo } \\
\text { vivencial }\end{array}$ \\
\hline
\end{tabular}

Estudio de impacto, 2013.

Cuadro 5. Ingresos mensuales por toda fuente en familias kamayoq

\begin{tabular}{lcclcc}
\hline \multicolumn{1}{c}{ Kamayoq de valle } & \multicolumn{3}{c}{ Kamayoq de altura } \\
& 2003 & 2012 & & 2003 & 2012 \\
\hline Venta de cuyes & 300 & Venta de fibra de alpaca & 10 & 200 \\
Engorde de ganado & & 300 & Venta de alpacas & 60 & 200 \\
Ingresos como kamayoq & & 100 & Venta de reproductores & & 200 \\
Venta de ovinos & 30 & 100 & Venta de papas nativas & 100 \\
Otros: venta de yogur, & & 150 & Venta de ovinos & 100 \\
miel, queso, otros & & & engordados & \\
Ingresos agrícolas & 20 & 50 & Ingresos como kamayoq & & 80 \\
Otras actividades & 100 & 50 & Otras actividades & 50 & 20 \\
\hline Total & 150 & 1050 & Total & 120 & 800 \\
\hline
\end{tabular}

Estudio de impacto, 2013.

Como se aprecia, el incremento en el nivel de ingresos en diez años es impresionante. Comparado con la situación inicial de pobreza en que vivían los campesinos, el incremento en el caso de los kamayoq de las comunidades del valle del Vilcanota es del 1000\%, y en el caso de los kamayoq de altura, del $667 \%$. Dentro de esta estructura de ingresos, el mayor peso sustancial de incremento lo tienen los emprendimientos, que representan el $81 \%$ y el $87,5 \%$, respectivamente. Dicho rubro ha inyectado el ingreso familiar con un monto de 700 a 850 soles por familia al mes. Es decir, si antes una familia contaba 
con un ingreso promedio de 200 a 300 soles, ahora su ingreso es de 800 a 1050 soles. Así, gracias a los emprendimientos, las familias de los kamayoq han aumentado sus ingresos en promedio en $833 \%$ en diez años, en un porcentaje promedio de $83 \%$ cada año.

Del total de 379 kamayoq capacitados, 160 (activos y no activos) han decidido por el camino de los emprendimientos, es decir, el $42 \%$ de los kamayoq ha decidido experimentar una nueva opción en sus vidas sobre una base material concreta (incremento de sus activos natural y físico). Esta experiencia los va a conducir a una serie de circunstancias favorables y desfavorables. Según las capacidades de cada kamayoq (activos humano y social), podrán dar respuesta a las vicisitudes y exigencias del mercado, el cual los irá incorporando, asimilando o descartando según sus leyes. Lo más importante para el kamayoq es que han visualizado una salida para su pobreza, un porvenir, lo que nunca antes tuvieron. Por ello la trascendencia de estos cambios. Aquí los testimonios:

Compro toretes, hago engordar y después los vendo y gano 50 soles por cada animal.

Yo tenía vacas criollas, pero las he cambiado por cruzadas y ahora a 800 soles vendo una vaca cada año.

Desde que tengo pasto cultivado solo crío ovejas merino; cada oveja vendo a 60 soles, antes solo tenía chusquitas que me compraban a 20 soles.

Dispongo para vender de cien cuyes mauro mina, dos toretes mejorados y diez ovejas caranegras para vender en el mercado; antes solo vendía animales criollos, pero no me rentaba, en cambio ahora me pagan buen precio.

\section{Actividades microempresariales}

Uno de los grandes cambios generados por el proceso de empoderamiento en las capacidades de los kamayoq por el contexto institucional ha sido el impulso de modelos de gestión empresarial que se han materializado en la creación de microempresas familiares o asociaciones de productores. La creación de microempresas familiares ha sido un salto tan audaz como exitoso que han dado ocho kamayoq (5\% del total), quienes han alcanzado esta posición por haber asumido el rol de productores altamente especializados o como ofertantes de productos transformados con valor agregado. Esto evidencia que solo otorgando valor a la producción o transformándola se puede lograr ingresos más altos para las familias. 
No es casual que los rubros en que han incursionado sean cuatro: crianza de cuyes, engorde de ganado, mejoramiento genético de ovinos y alpacas y producción de derivados lácteos. Todos ellos funcionan articulados a su finca familiar y están instalados en sus viviendas, donde intervienen activamente los demás miembros de la familia. En sus casas se encuentran todas las instalaciones y equipos que los kamayoq han construido o mejorado.

Las características de estas microempresas familiares son:

- Están basadas en el incremento del capital natural familiar.

- Requieren una inversión de capital.

- Usan intensivamente mano de obra familiar.

- Demandan créditos con frecuencia.

- Tienen una amplia red social.

- Cuentan con estabilidad familiar.

- Cuentan con calidad de vida.

Lo interesante de esta opción es que casi todos lo han hecho de manera progresiva, autodidacta y sustentada en sus emprendimientos previos, lo que evidencia que, cuando una propuesta formativa está bien orientada y encaja con las necesidades de la población, eleva a las personas en su crecimiento económico, social y personal, es decir, las forma para toda la vida.

Aquí un testimonio 5 :

En junio del 2001 hemos constituido Agroindustrias COMERSUR de la comunidad de Sunchuchumo entre once familias de kamayoq residentes en la comunidad y gestionamos ante el proyecto Corredor, mediante un plan de negocios para la producción de lácteos. Nos dieron 14000 soles. Corredor aportó el $90 \%$ y los socios el $10 \%$. Este monto fue utilizado en la capacitación para la gestión empresarial, comercialización y producción de yogur. De esta microempresa han quedado solo tres kamayoq (los demás se retiraron por no pagar el aporte del $10 \%$ ), que somos los que actualmente comercializamos yogur de manera individual, pero la producción lo hacemos en grupo, sacamos 80 litros diarios. La leche que tenemos no abastece y compramos de otras familias. De un litro de leche sacamos tres litros de yogur, por eso nuestra ganancia es de 3,2 por litro (un promedio de 80 soles diarios). Actualmente nos hemos formalizado las tres familias con una Junta Directiva y registros públicos; mensualmente nos reunimos para evaluar las ventas producidas bajo una sola marca, para fijar precios y así evitar hacerse com-

5 Recogido de la evaluación de impacto realizada por el proyecto Corredor Puno-Cusco (Zutter y otros, 2010). 
petencia. Ahorita estamos aprendiendo para hacer (María Huamán Quispe, kamayoq Sunchuchumo).

Como se aprecia, la conformación de microempresas varía según el rubro. Se conforman con otros socios en los casos de derivados lácteos por la necesidad de abastecerse de leche; en el caso de los cuyes, la opción es constituir microempresas familiares. Lo interesante de los casos es que cada kamayoq se ha insertado en el mercado y son conscientes de que deben seguir mejorando en la calidad de sus productos, en la formalización, en el acceso a créditos, y seguir informándose sobre la oferta y demanda para diversificar su producto y seguir siendo competitivos.

Con relación al tipo de microempresas creadas y en funcionamiento por los kamayoq, estas son: microempresas de derivados lácteos, tres; microempresas de cuyes, tres, y microempresas de engorde de ganado, dos. Las características de la microempresas indicadas es que están sostenidas en la participación de los miembros de la familia; los kamayoq tienen más años de educación formal, cuentan con mejores condiciones de vida, tienen más del doble de activos del hogar, participan en mayor número de organizaciones y tienen acceso al mercado crediticio. El tránsito hacia convertirse en emprendedor no es fácil: requirió mucho apoyo institucional y una fuerte inversión personal. Ello implica que solo algunos kamayoq sean «exitosos».

\section{Contexto para los emprendimientos}

En el período 1998-2009 existió un conjunto de instituciones públicas y privadas que favorecieron el desempeño de los kamayoq. Dicha coyuntura permitió una participación muy activa de los asociaciones de productores promovidas por el proyecto Corredor Puno-Cusco, que contó con la participación de los municipios distritales como instituciones comprometidas en promover y facilitar los procesos productivos en articulación con otros actores, creando condiciones adecuadas en la prestación de servicios de asistencia técnica, desarrollo de capacidades técnicas y de gestión, financiamiento y organización, tal como se aprecia en el cuadro 6 . 


\section{Cuadro 6}

\begin{tabular}{ll}
\hline Tipos de organizaciones & Nombres \\
\hline Organismos públicos & Dirección Agraria; PRONAMACHCS; \\
& SENASA; ATDR \\
\hline Organismos no gubernamentales & Proyecto Corredor Puno-Cusco \\
& Cáritas; Programa Empleo Juvenil PAC; \\
& Visión Mundial; IPID; ITDG; INTERVIDA; \\
& IAA; SOLARIS, HPI \\
\hline Organismos comunales y gremiales & CONACS \\
\hline Asociaciones de productores & De cuyes, papas, engorde de ganado, artesanía \\
\hline Otros & Registros Públicos, RENIEC, SUNAT, \\
& SUNART, ADUANAS, Banco de la Nación, \\
& CREDINKA, Caja Municipal Cusco, Caja \\
& Municipal Arequipa \\
\hline
\end{tabular}

Fuente: Equipo técnico CONVEAGRO, 2012

\section{En el capital humano}

La forma como los promotores kamayoq iniciaron su transformación en términos de información, conocimientos, aprendizajes, modos de ver la vida y perspectivas a futuro tiene que ver con un aspecto esencial: haber ingresado a la «luz del conocimiento», considerando que estructuralmente viven en una situación de exclusión social, marginación y racismo. Los campesinos encontraron en la «Escuela de kamayoq» la posibilidad de una «puerta» que les posibilitase el acceso al conocimiento útil, práctico y acorde con su realidad de economía campesina para hacer frente a una sociedad competitiva y a un Estado indiferente. Es así como, en el proceso de capacitación, los campesinos descubren enormes posibilidades de «salir adelante en la vida» sin mayores costos y sin dejar de ser campesinos andinos.

Todos los promotores expresaron que el hecho de ser kamayoq les había abierto mejores oportunidades para potenciar sus capacidades personales (que tenían en estado latente) para transformarse en tres campos, como veremos a continuación. 


\section{Mejora de autoestima y seguridad personal}

Los cambios y transformaciones ocurridos en las familias de los kamayoq se relacionan con el incremento de sus capitales y activos, cuya aplicación en su vida práctica ha generado un conjunto de efectos multiplicadores en la seguridad material y personal para seguir adelante en su lucha por salir de sus condiciones de pobreza. Esto significa haber tomado una actitud proactiva frente a las vicisitudes cotidianas y estructurales y levantarse sobre la base de sus capacidades mejoradas y validación de su aplicación en sus predios.

Los testimonios hablan por sí solos:

Sí, porque ser kamayoq ha cambiado mi vida gracias a las capacitaciones que me dieron, ya no tengo miedo de hablar en público y puedo ir a otras comunidades vecinas y trabajar para mi propio beneficio. Como kamayoq tengo más conocimientos, ya no soy igual que los demás porque ahora tengo mayor conocimiento y más posibilidades de progresar. Ahora soy otra persona. Desde que estuve en la «Escuela de kamayoq» he vuelto más participativo y entusiasta (Salomón Catunta, comunidad Chapichumo).

Estas expresiones nacen justamente de un proceso que llamamos «empoderamiento» personal alcanzado, fruto del debate, la reflexión individual, el interaprendizaje y el análisis grupal. Todo ello ha formado en el kamayoq «factores de protección interna» del individuo frente a los riesgos económicos y políticos, así como frente a la injusticia, racismo, rechazo y marginación social de que son víctimas cotidianamente.

Uno de esos factores de protección ha sido la «Escuela de kamayoq», donde el kamayoq se dotó de herramientas técnicas, pero también de herramientas emocionales que ha ido construyendo y redescubriendo en su formación, gracias a la propuesta pedagógica y a los contenidos allí trabajados. Estos aspectos han permitido que se genere la autoestima como un núcleo central de la personalidad del kamayoq, de naturaleza esencialmente valorativa y emocional vinculada con el reconocimiento social. Este sentimiento de «ser alguien que vale» ha sido un fuerte impulsor de conductas constructivas proactivas que los han impulsado a asumir riesgos y a procesar las frustraciones y retroalimentarse en sus objetivos de progresar sobre la base de sus capacidades mejoradas.

Entonces consideran que deben ser «competitivos» bajo el concepto de «ser bueno en algo», «buen técnico», «capaz», y eso precisamente ha ayudado a muchos kamayoq a salir fuera de sus casas y de la comunidad para trabajar instrumentados por su conocimiento tecnológico. Dicha autoeficacia genera un 
sentimiento de satisfacción tremendamente importante para campesinos que nunca han recibido el reconocimiento de la otra sociedad (urbana-mestiza).

En tal sentido, una adecuada autoestima supuso el reconocimiento de las habilidades, destrezas y conocimientos, pero también de las limitaciones, manteniendo un sentimiento básico de ser valioso. Es eso precisamente lo que les ha insuflado la «Escuela de kamayoq» a partir de una propuesta formativa que combinaba lo tecnológico con lo humanístico. Aquí un esquema de dichos cambios:

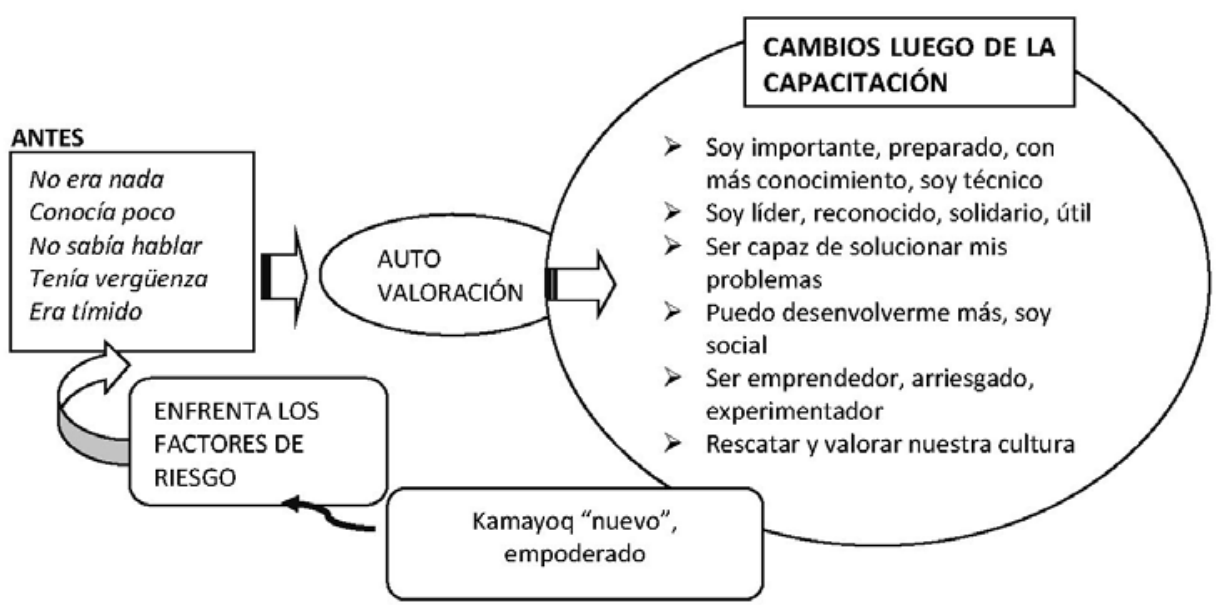

\section{Ampliación de su mundo sociocultural}

Otro elemento fundamental en el proceso de empoderamiento — es decir, «adquirir poder» desde la visión de los kamayoq — ha sido ampliar su mundo sociocultural restringido al ámbito comunal y campesino. Es precisamente durante la capacitación cuando tuvieron la oportunidad de participar en una serie de eventos, pasantías, ferias, concursos e intercambio de experiencias a centros de experimentación de la universidad, módulos exitosos de otras familias donde han conocido otras ciudades, nuevas instituciones, y se han relacionado con profesionales y técnicos que les han abierto oportunidades de conocer personas y agentes económicos con quienes establecer relaciones tecnológicas y actividades comerciales propias de la sociedad urbana. Es en estos espacios donde empiezan a descubrir nuevos códigos, símbolos y formas de comportamiento para surgir; incorporan en su forma de ser valores como el ser eficiente, eficaz, planificador, ordenado y cuidadoso, cuyo resultado será «aprender a ser competitivo». 
Un ejemplo concreto es que los kamayoq aprendieron las técnicas del mejoramiento genético de animales, manejo de insumos veterinarios o producir pastos cultivados, conocimientos nunca antes manejados, y luego de aplicarlos, aprecian resultados inmediatos, de los cuales se apoyan para despegar. Aquí tenemos este testimonio:

Estoy más preparado, despierto, más capaz, porque la capacitación nos ha dado oportunidades para participar en las ferias; en mis relaciones he mejorado mucho, especialmente con personas que nunca había conocido. Así, gracias a los ingenieros que me han orientado, he aprendido a hacer inseminación artificial, ahora gano bastante en eso. Ahora pienso ampliar en mi casa, corrales para empezar a criar cuyes, y en mi estancia de la altura mejorar mis alpacas reproductoras, para eso he ido al proyecto Corredor, para que me dé un préstamo para comprar nueva plantilla de alpacas (Fermín Huamantalla, comunidad Toxacota, Marangani).

\section{Consolidar sus posibilidades de enfrentar la vida}

El proceso de mejoramiento de capacidades humanas que tuvieron los kamayoq a partir de su formación técnica agropecuaria, complementada con una formación humanística, permitió que en ellos se produzca una acumulación de capacidades, dado que redescubrieron sus propias potencialidades como resultado del respaldo institucional de la ONG, de la organización comunal a la cual pertenecían y del resto de la sociedad, que empezaron a contratarlos como «técnicos agropecuarios». Esto afianzó en ellos el hecho de que tenían una base para enfrentar la vida, no estaban con la manos vacías, situación que los impulsó a trabajar fuera de sus comunidades con seguridad, apoyados en una fuerza motriz que fue la asimilación tecnológica, que posteriormente los impulsó a la innovación como factor fundamental para competir en su articulación al mercado.

No fue casual que la mayoría de ellos se atreviera por primera vez en su vida a emprender negocios con seguridad, situación sustentada en los aprendizajes innovadores que pusieron en práctica y que les permitieron: (i) afirmarse individualmente; (ii) adquirir una valoración sociocultural, y (iii) adquirir el reconocimiento social de los varones y mujeres del medio rural.

Todo ello evidencia la significativa transformación que ha ocurrido en los últimos años de dar un mayor reconocimiento al papel del «capital humano» y ayuda a entender la pertinencia de la perspectiva de las capacidades. Si una persona llega a ser más productiva en la producción mediante una mejor educación, 
no es descabellado esperar que también pueda dirigir mejor su propia vida y tener más libertad para hacerlo. Ambas perspectivas ponen la expansión de capacidades humanas en el centro de la atención. Dichos aspectos son de tremenda importancia, dado que para un campesino de la zona el lograr ese tipo de cambio normalmente le lleva veinte, treinta años o toda la vida, en cambio los kamayoq lo alcanzaron en ocho a diez años.

En el capital social

El concepto de capital social se define como «el conjunto de normas, instituciones y organizaciones que promueven la confianza y la cooperación entre las personas, las comunidades y la sociedad en su conjunto». En el caso de los kamayoq, implica las redes de parentesco, la afiliación a asociaciones de productores, pertenencia a organizaciones y las relaciones sociales con autoridades y funcionarios de instituciones públicas y privadas. A partir de los resultados del estudio, tenemos que el capital social generado por los kamayoq ha sido a partir de relaciones culturalmente afines y la ampliación de redes sociales.

Las relaciones culturalmente afines están originadas por las funciones de los kamayoq como proveedores de asistencia técnica a otras familias comuneras (primero en su comunidad de origen y luego fuera de ella), que han generado y desarrollado los vínculos de confianza entre las familias vecinas conectadas a su mundo de relaciones familiares y comunales. En este relacionamiento funciona un conjunto de factores que van más allá de la simple relación personal, pues intervienen factores de orden histórico, emocional, religioso y de parentesco. Esto resulta mucho más profundo y significativo porque está adscrito a vínculos de tipo cultural y territorial, dado que tanto los kamayoq como sus vecinos son parte de la misma cultura y de las relaciones interculturales existentes en la sociedad.

Nos referimos a que los kamayoq han generado un «capital social» en el marco de dos niveles: redes intracomunales y extracomunales.

Redes intracomunales

- Relaciones con las familias que viven en su comunidad.

- Relaciones con las familias-clientes de otras comunidades.

- Compromisos frente a otras comunidades.

- Relaciones por sus fincas usadas como vitrinas.

El primer nivel de relaciones construidas por los kamayoq ha sido el de las redes familiares dentro de su comunidad, a partir de brindar servicios de asistencia 
técnica gratuita a las familias, compromiso que fue aceptado en asamblea cuando la comunidad los propuso para que se capacitaran. Estas relaciones con la comunidad tienen la lógica de reciprocidad, dado que fue la comunidad quien los propuso para capacitarse. Entonces debían realizar ayni para corresponder a ello.

Al predominar dentro de la comunidad el control social de los directivos y de las demás familias, en este espacio es normal que el kamayoq iniciado tenga buenas opiniones de su trabajo y también críticas; para ello, su apoyo es el tronco familiar y sus ramas como soporte para enfrentar —en muchos casos-las críticas, burlas y desconfianzas en el desempeño como oferente de asistencia técnica. No son casuales expresiones como la siguiente:

De acuerdo al compromiso con la institución yo doy el servicio a las familias de mi comunidad primero y luego a otras comunidades; en este trabajo a veces en la comunidad me critican y se burlan, no aceptan que yo sea un técnico. Entonces mis familiares me respaldan porque ellos me tienen más confianza; eso me ayuda mucho para seguir adelante y no desanimarme. También hay otras familias que sí valoran mi trabajo y me pagan voluntariamente, a veces resaltan mi trabajo en la asamblea, son bien agradecidos.

El segundo nivel de capitalización social tiene que ver con las familiasclientes, con las cuales establecen vínculos sustentados en criterios de eficiencia de la asistencia técnica; si esta funciona, entonces las afectividades crecen, la confianza, el cariño se manifiesta y se fortalecen las reciprocidades e intercambios. Cuando el kamayoq conquista un espacio por su eficiencia, entonces reafirma su valía y capacidades y continúa con más fuerza sus actividades y negocios.

Cuando doy asistencia técnica a las familias que me solicitan, siempre me tratan bien, me ven como alguien que comparte sus conocimientos. Siempre me valoran y también ellos aprenden, me ven como un líder, como una persona capaz, apta para realizar cualquier trabajo, me ven con respeto, como alguien que sabe más y pueden confiar sus animales porque yo les llevo medicinas. Me agradecen por el servicio que les doy, me pagan con cariño lo que les pido.

El tercer nivel de relaciones de los kamayoq es con referencia a otras comunidades, pues viajan para realizar actividades de capacitación como cursos, prácticas haciendo días de campo, participan en las asambleas, informan y orientan técnicamente a la comunidad. Estas relaciones permiten al kamayoq iniciado ampliar su «prestigio» en el ámbito distrital a otros, pero lo más importante para el kamayoq es sentir el reconocimiento social a sus capacidades de proveedor de asistencia técnica. 
Finalmente, el cuarto nivel de redes son sus vínculos con personas de diverso origen social del mundo rural para visitar sus predios familiares, debido a que los kamayoq — como parte de otro compromiso con la institución formadoradeben aplicar en sus propias fincas familiares todas las técnicas aprendidas. Fue así como ellos instalaron en sus parcelas todo el conjunto de semillas mejoradas, preparación de abonos, instalaciones para crianzas, mejoramiento genético, biohuertos y otros, que llamaron la atención de las demás familias por tratarse de «fincas vitrina» y causaron admiración por su diseño y planificación (veremos la ampliación de este punto cuando tratemos el capital natural y físico).

En este espacio, también el kamayoq adquiere un prestigio de ser «buen técnico»; entonces, es bien valorado y la solicitud de sus servicios es continua. Pero lo más importante para ellos es que «otras personas les reconocen su trabajo, sus saberes». En tal sentido, el sentirse reconocidos socialmente es un aspecto sumamente valioso para campesinos indígenas, quienes históricamente han sufrido relaciones de dominación y discriminación cultural. En muchos casos, dichas parcelas han sido objeto de visitas, intercambios y pasantías para instituciones de desarrollo rural, tal como ha ocurrido con el kamayoq Germán Cruz, de la comunidad de Ccuyo, quien ha destacado por producir 3000 cuyes y ser criador de reproductores, crianzas que ha combinado con la producción de pastos, abonos orgánicos y concentrados, además de realizar mejoras en sus instalaciones de su vivienda en Marangani.

\section{Redes extracomunales}

Los kamayoq han impulsado la conformación de una asociación y se han acercado a las autoridades e instituciones. Esta asociación, denominada Toribio Quispe Jallo, es una organización con personería jurídica inscrita en registros públicos que asocia a los egresados de la «Escuela de kamayoq». Tiene la finalidad de dar un espacio de encuentro a los kamayoq egresados de la escuela, de canalizar los problemas e iniciativas de los egresados asociados, de mantener la unidad fomentando identidad profesional y cultural, y de abrir espacios laborales en otros ámbitos mediante concursos de plazas para kamayoq oferentes de servicios y de brindar información de mercados para la producción microempresarial de kamayoq.

Otro aspecto esencial en el establecimiento de sus redes sociales extracomunales ha sido el vínculo con instituciones públicas, proyectos especiales, ONG y empresas privadas canalizadas a través de ITDG, quien se ha encargado de «reco- 
mendarlos» para que sean contratados como «técnicos especialistas» en dichas instituciones en períodos de seis meses a tres años en lugares como Apurímac, Arequipa, Ayacucho, Puno y provincias del Cusco. Esta circunstancia de «salir de su comunidad para trabajar» ha sido un aspecto esencial en el desarrollo de la autoestima de los kamayoq y afirmación de que todo el aprendizaje adquirido tiene frutos, haciéndolo valorar con más fuerza la importancia de la educación técnica-rural como mecanismo de ascenso social y mejora de la producción agropecuaria de las economías campesinas.

Otro elemento coyuntural importante para los promotores en sus relaciones sociales fue contar con la presencia del proyecto Corredor Puno Cusco, institución que durante seis años impulsó la formación de grupos de interés (asociaciones de productores) para generar planes de negocios que fueron financiados a través de asignaciones de recursos a los grupos, quienes lograron impulsar diversos emprendimientos bajo esta modalidad. Dicha institución proporcionó créditos y capital fresco para el inicio de emprendimientos, lo cual afianzó la necesidad de contar con instancias crediticias para poder "progresar» más rápidamente.

Estos procesos son los que precisamente se han dado al insertar a los kamayoq en el plano institucional y societal; es decir, han comenzado a relacionarse con esferas extracomunales para el ejercicio de sus emprendimientos, como por ejemplo ir a las municipalidades y hacer gestiones para conseguir financiamientos, o acercarse a las instituciones, empresas y ONG y financiarse cursos para perfeccionarse en diversos rubros del conocimiento técnico y de mercados. Para ello un requisito era que conformaran «grupos de interés» y promoviesen el asociativismo microempresarial, de manera que comiencen a familiarizarse con los instrumentos y códigos del mercado.

\section{ESTRATEGIAS APLICADAS POR LOS KAMAYOQ PARA EL INCREMENTO DE SUS ACTIVOS}

La ONG buscó atender la situación de la oferta y demanda de servicios rurales. Para ello, se orientó a formar extensionistas andinos cuya virtud fue tener una formación tecnológica y culturalmente ser pertinentes a la realidad de la economía campesina. De esa manera se solucionaría el abandono estatal de la extensión rural y la carencia de oferentes de asistencia técnica agropecuaria para los pequeños productores, contando con un ejército de proveedores de asistencia técnica. Así se 
contribuiría a incrementar los niveles de manejo tecnológico y, por consiguiente, lograr la apertura de mercados de trabajo y de servicios, haciendo que los campesinos se inserten de mejor manera a dichos mercados y estén dispuestos a pagar dichos costos. El supuesto era que a futuro estos líderes experimentadores fuesen parte de un sistema organizado de extensión técnica rural en el ámbito regional. En esa medida, los kamayoq se insertarían a cadenas productivas y asumirían el rol de gestores del desarrollo rural endógeno.

Lo que nunca imaginó la ONG fue que para los campesinos esta perspectiva de desarrollo rural no era un fin sino un medio, es decir, un camino (viable y factible) para insertarse en una propuesta institucional pero cuyo fin era totalmente personal del campesino promotor, orientado a su progreso familiar y como un mecanismo para salir de su pobreza. Los kamayoq, desde su óptica de campesinoproductor y premunidos de una visión del mundo culturalmente andino-indígena , entendían y leían la «Escuela de kamayoq» como un medio para instrumentarse técnicamente que les permitiese generarse ingresos y ulteriormente mejorar su calidad de vida. En su visión de desarrollo nunca estuvo planteada la perspectiva de «vivir de los ingresos como proveedor de asistencia técnica» a las familias campesinas del ámbito provincial, sino que asumía esta actividad como una etapa más de su objetivo mayor.

Las estrategias que han usado casi todos los kamayoq ha sido la siguiente:

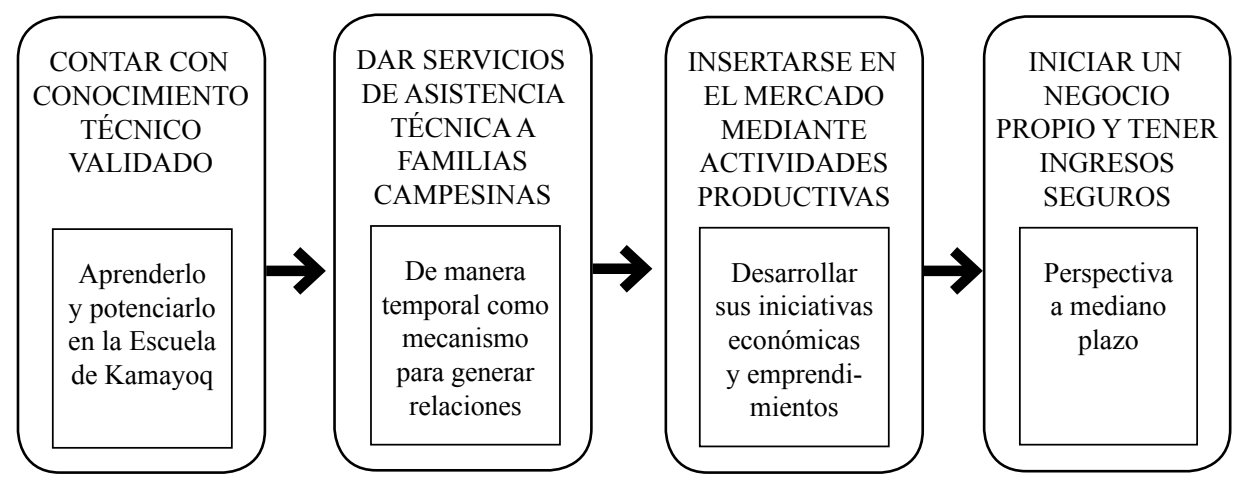

\section{PROCESO DE ACUMULACIÓN DE ACTIVOS}

En cuanto a los activos de los kamayoq, los impactos más significativos han sido resultado de un conjunto de encadenamiento de procesos que han tenido un origen y luego se ha multiplicado generando impactos en los demás capitales. Nos 
explicamos. El eje central dinamizador de las transformaciones más impactantes en la vida de los kamayoq ha sido la ampliación de sus conocimientos, habilidades y destrezas (capital humano), desarrollando y liberando todo su potencial latente, con saberes pertinentes, inherentes y adecuados a las condiciones del pequeño agricultor quechua del valle del Vilcanota provenientes de la ciencia moderna y del diálogo de saberes, que le fueron transferidos de manera pedagógicamente adecuada.

Este hecho impactó en la generación de una serie de «aperturas de oportunidades» y alternativas de solución a los principales problemas del agricultor andino que el kamayoq capitalizó y convirtió en posibilidades de autoempleo, a partir de la aplicación en su predio (capital natural) de las capacidades ampliadas, y cuya expresión se objetivizó en la mejora de la calidad de sus recursos y la mayor disponibilidad de estos (pastos cultivados, compra de ganado mejorado, disponibilidad de pasto, riego por aspersión, mejoramiento de suelos con abonamiento natural). Ello permitió que la familia del kamayoq empiece a incrementar sus rendimientos y sus ingresos mediante la cadena del valor y, consiguientemente, tenga mayor disponibilidad de inversión y acceso a otras fuentes financieras para incrementar sus activos o pagar sus deudas (capital financiero).

\section{Proceso de acumulación de activos en los kamayoq}
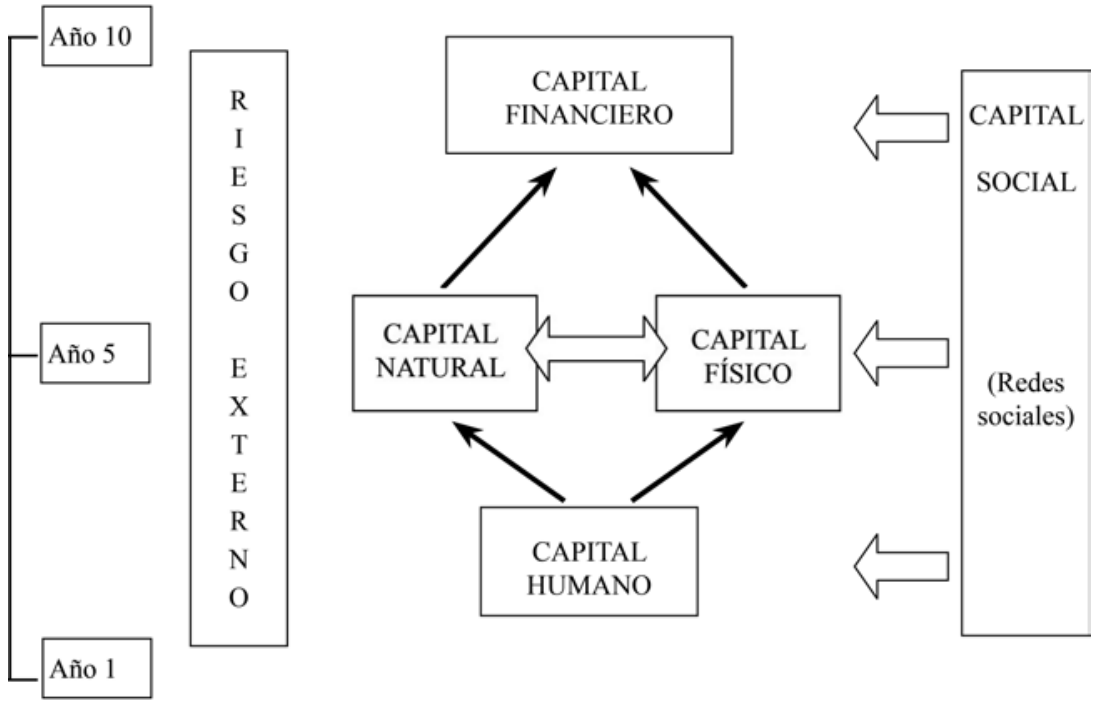
Con los recursos económicos disponibles, las familias del kamayoq activaron la posibilidad de invertir, adquiriendo bienes de capital, instalaciones, equipos e implementos imprescindibles para generar riqueza (capital físico) y cuyos excedentes sirvieron para adquirir también bienes de consumo para el bienestar familiar. Todo este encadenamiento de factores de producción ha estado siempre bajo el control, gestión y administración del kamayoq, pero para hacerlo más eficiente debía recurrir a generar redes y conexiones y participar en grupos de interés (capital social) quienes otorgaron el soporte de relaciones de confianza e intercambios al sistema estructurado.

En resumen, los kamayoq han logrado establecer un conjunto de mecanismos de protección, defensa y resiliencia para enfrentar las dificultades estructurales y factores de vulnerabilidad a las que están sujetos todos los productores rurales de la zona, cuyos mayores alcances son los siguientes:

- Se han vuelto más capaces de transformar realidades adversas y de protagonizar la solución de sus propios problemas.

- Han elevado la productividad de la mano de obra familiar, con lo cual han incrementado sus activos.

- Han creado condiciones efectivas de introducir innovaciones tecnológicas, gerenciales y organizativas en tres eslabones de la cadena agroalimentaria.

- Los kamayoq han cambiado de actitud y valores, abandonando determinismos fatalistas y asumiendo acciones proactivas sustentadas en alta autoestima.

\section{IMPACTOS EN LA CALIDAD DE VIDA DE LOS KAMAYOQ}

Dentro del enfoque del desarrollo humano, se considera la calidad de vida como el grado de bienestar que experimentan las personas o familias; también se considera así a la manera de vivir, de ser y de relacionarse con la sociedad y el medio ambiente. En resumen, el enfoque de las capacidades defiende que el nivel de bienestar depende del conjunto disponible de capacidades para funcionar y, por este motivo, el bienestar, en estrecha conexión con la noción ética de «vida buena» (en términos andinos el Allin Kausay), que significa un conjunto de variables objetivas y subjetivas con las cuales precisamente lograron los kamayoq incrementar su desarrollo humano. En el caso de los campesinos kamayoq, el concepto de calidad de vida significa familia feliz, lo que significa contar con alimento seguro, vestido, vivienda, vivir en familia y establecer relaciones sociales con los vecinos, cuyo proceso de adquisición es como sigue: 


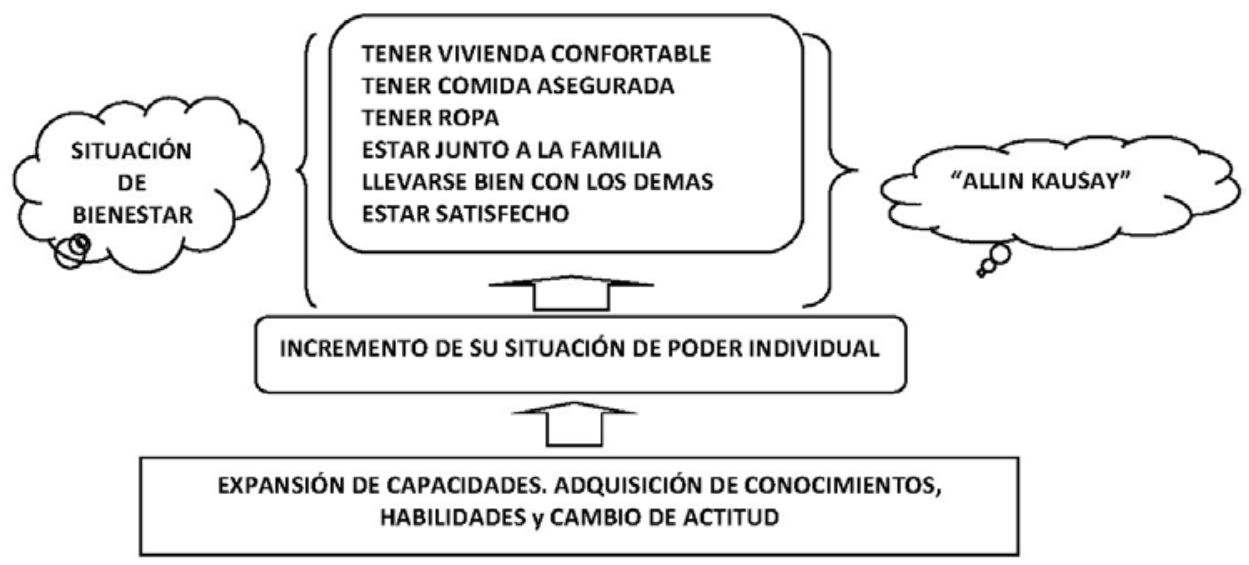

\section{CONCLUSIONES}

1. El incremento de las capacidades de los kamayoq ha permitido que estos dispongan de conocimientos y capacidades técnicas como instrumento para defenderse en la vida, que luego de validarlo en sus fincas, lo primero que les permitió alcanzar fue la seguridad alimentaria, a partir del incremento de sus activos naturales.

2. Los promotores han realizado una inversión económica creciente en sus predios, derivada de la aplicación de sus conocimientos y del incremento de ingresos alcanzado. La mayoría de kamayoq ha realizado mejoras para nuevas actividades productivas para su vinculación con el mercado.

3. Se han ampliado las redes sociales e institucionales del kamayoq en su conocimiento de nuevas opciones para seguir capacitándose y mejorar sus posibilidades de empoderarse mejor, lo que ha elevado su autoestima por el mejoramiento de sus capacidades, el reconocimiento de sus familias, de la comunidad y fuera de ella.

4. Ha mejorado la calidad de vida de las familias, expresado en mayor acceso de los hijos a la educación secundaria y superior, en mayor adquisición de bienes de consumo y de capital, en la mejora de sus viviendas y la armonía familiar. 


\section{REFERENCIAS BIBLIOGRÁFICAS}

Castillo, Marlene (1999). Viabilidad de la asistencia agrícola privada a pequeños agricultores de la costa de la región Grau. Piura: Centro de Investigación y Promoción del Campesinado.

CBC (1985). Estrategias para el desarrollo de la sierra. Cusco: UNAM, CBC.

Coordinadora Rural (1992). Una estrategia campesina de desarrollo: primera y segunda parte. Serie Cuadernos Andinos. Lima: IAA.

De la Torre, Carlos (2004). Kamayoq, promotores campesinos de innovaciones tecnológicas. Lima: ITDG-MASAL.

FAO (1993). Desarrollo rural. Soluciones simples para problemas complejos. Programa de Cooperación Técnica. Oficina Regional de la FAO para América Latina y el Caribe.

Figueroa, Adolfo y otros (1997). Pequeña agricultura en el Perú, presente y futuro. Lima: PACT.

Plaza, Orlando (2002). Esquema conceptual para el desarrollo rural. Una propuesta para la discusión final. Inédito. Lima, diciembre.

Ramsay, Jorge (1997). Lo clásico y lo moderno en extensión agrícola. Fascículo Técnico del Centro Regional Andino. Lima: IICA.

Sen, Amartya (2000). Desarrollo y libertad. Barcelona: Planeta.

Soberón, Luis (1994). Evaluación de programas sociales. Teoría y metodología de la investigación evaluativa en curso «Evaluación social de proyectos». IIUR.

SEPIA IX (2002). El problema agrario en debate. Lima: Universidad Nacional del Altiplano. SEPIA.

Urrutia, Jaime (2002). Espacio, poder y mercado: preguntas actuales para una vieja agenda. En SEPIA, IX. Lima.

Van Immeerzeel, W. (2003). Pachamama Raymi la fiesta de la capacitación. Teoría y práctica de un sistema de capacitación campesino a campesino. La Paz: MASAL, DEXCEL. 